DISTRIBUTION STATEMENT A. Approved for public release; distribution is unlimited.

\title{
Ocean Dynamics: Vietnam DRI
}

\author{
Robert Pinkel \\ Marine Physical Laboratory \\ Scripps Institution of Oceanography \\ La Jolla California 92093-0213 \\ Phone: (858) 534-2056 email: rpinkel@ucsd.edu \\ Drew Lucas \\ Marine Physical Laboratory \\ Scripps Institution of Oceanography \\ La Jolla, CA 92093 \\ phone: (858) 822-2580 email: ajlucas@ucsd.edu
}

Award: N00014-12-1-0635

\section{LONG-TERM GOALS}

To gain a more complete understanding of ocean dynamical processes, particularly at fine-scale, through comparison of high, mid- and low-latitude observations, near the sea surface, in the main thermocline, and near the sea floor.

\section{OBJECTIVES}

To identify the phenomena involved in the cascade of energy from mesoscales to turbulent scales. In particular, we wish to quantify the relationship between fine-scale background conditions and the occurrence of microscale breaking.

\section{APPROACH}

Progress is achieved through a steady-state cycle of instrument development, field observation and data analysis. The primary instruments employed include Doppler sonar, rapidly-profiling CTD's, and ocean-wave-powered vertically-profiling Wirewalker floats. Our instruments produce information that is quasi-continuous in space and time, typically spanning two decades in the wavenumber domain. This broadband space-time coverage enables the investigation of multi-scale interactions.

\section{WORK COMPLETED}

In July 2011, we explored an outflow channel between Batan and Diogo Islands in Luzon Strait as an aspect of the IWISE DRI, Figure 1. Intense internal lee waves were established in the channel as the eastward $3 \mathrm{kt}$. tidal-current exited the Strait into the deeper Pacific, Figure 2. We used the HDSS sonars and the Fast CTD to document flow evolution at four stations along the channel over a period of 1-3 tidal cycles, each. Intense mixing was seen at depths $1200 \mathrm{~m}$ above 


\section{Report Documentation Page}

Form Approved

OMB No. 0704-0188

Public reporting burden for the collection of information is estimated to average 1 hour per response, including the time for reviewing instructions, searching existing data sources, gathering and maintaining the data needed, and completing and reviewing the collection of information. Send comments regarding this burden estimate or any other aspect of this collection of information,

including suggestions for reducing this burden, to Washington Headquarters Services, Directorate for Information Operations and Reports, 1215 Jefferson Davis Highway, Suite 1204, Arlington

VA 22202-4302. Respondents should be aware that notwithstanding any other provision of law, no person shall be subject to a penalty for failing to comply with a collection of information if it

does not display a currently valid OMB control number.

1. REPORT DATE

30 SEP 2014

4. TITLE AND SUBTITLE

Ocean Dynamics: Vietnam DRI

6. $\operatorname{AUTHOR}(\mathrm{S})$

7. PERFORMING ORGANIZATION NAME(S) AND ADDRESS(ES)

University of California San Diego,Scripps Institution of Oceanography,9500 Gilman Drive,La Jolla,CA,92093

9. SPONSORING/MONITORING AGENCY NAME(S) AND ADDRESS(ES)

3. DATES COVERED

00-00-2014 to 00-00-2014

5a. CONTRACT NUMBER

5b. GRANT NUMBER

5c. PROGRAM ELEMENT NUMBER

5d. PROJECT NUMBER

5e. TASK NUMBER

5f. WORK UNIT NUMBER

8. PERFORMING ORGANIZATION

REPORT NUMBER

10. SPONSOR/MONITOR'S ACRONYM(S)

11. SPONSOR/MONITOR'S REPORT

NUMBER(S)

12. DISTRIBUTION/AVAILABILITY STATEMENT

Approved for public release; distribution unlimited

13. SUPPLEMENTARY NOTES

14. ABSTRACT

15. SUBJECT TERMS

16. SECURITY CLASSIFICATION OF:

a. REPORT

unclassified b. ABSTRACT

unclassified c. THIS PAGE

unclassified
17. LIMITATION OF ABSTRACT

Same as

Report (SAR)
18. NUMBER 19a. NAME OF

OF PAGES RESPONSIBLE PERSON

13

Standard Form 298 (Rev. 8-98) Prescribed by ANSI Std Z39-1 
the topography, with deeper overturns of height $\sim 200 \mathrm{~m}$ not uncommon. Strong winds coupled with the tidal currents made ship-handling difficult during this study.

Major subsequent effort involved participation, along with other DRI PIs, in the negotiation process that would hopefully allow a UNOLS research vessel to work in Vietnamese waters in Spring 2013. This was planned to be an educational cruise, and we were preparing a Wirewalker profiling float and a Livewire power-generating float for the educational deployments. Unfortunately, we were unsuccessful in obtaining the required permission from the Vietnamese Government, and the Spring 2013 cruise was redirected, on short notice.

We returned to this outflow channel to further explore the non-linear structures associated with mid-water breaking. This time, we "surfed" the tidal currents on the Revelle, achieving spatial transects of the evolving flow. Analyses of these data are in process, as an aspect of the $\mathrm{PhD}$ thesis of Ruth Musgrave.

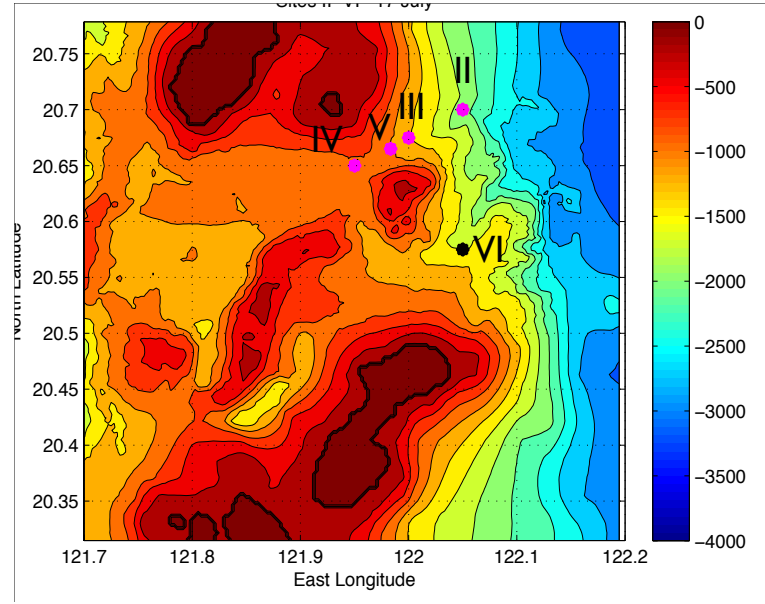

Figure 1. A map of the north outflow channel between Diogo and Luzon Islands. Stations indicated were sampled in July 2011. In 2013, we repeatedly traversed the channel, obtaining spatial transects with the Fast CTD and Hydrographic Doppler Sonar as the flow evolved.

As an aspect of the analysis, depth-time maps of eddy diffusivity (Figure 2, left and center) can be produced from Thorpe-scale analysis of the temperature and density fields (Dillon, 1983). Given the large vertical scale of the dominant overturns, the vertical resolution of the CTD $(2 \mathrm{~m})$ is not an issue and the eddy diffusivity estimates based on temperature and density agree remarkably well. Diffusivities are a factor of 100-1000 above open ocean values. Depthintegrated dissipation rates exceed $1 \mathrm{~W} / \mathrm{m}^{2}$.

As an independent check, we can watch these turbulent processes as they modify the mean salinity profile of the Western Pacific (Figure 2 right). The profile features regions of pronounced positive and negative curvature. A selection of profiles is plotted over a single 24hour tidal cycle. Salinity (spice) fluctuations are calculated in isopycnal coordinates, such that vertical advection by internal waves contributes minimally to the variability.

Recalling:

$$
D S / D t=-\kappa_{S} \partial^{2} S / \partial z^{2}=-\kappa_{S} *(\text { salinity profile curvature })
$$

We take $D S / D t \sim d S_{r m s} / 24$ hours and find $\kappa_{S}=0.042$ for the $100-350 \mathrm{~m}$ depth range and $\kappa_{S}=0.096$ for the 350-900 m range (cyan bars Fig 3 center). Agreement with the Thorpe-scale estimates of diffusivity is rather remarkable. 


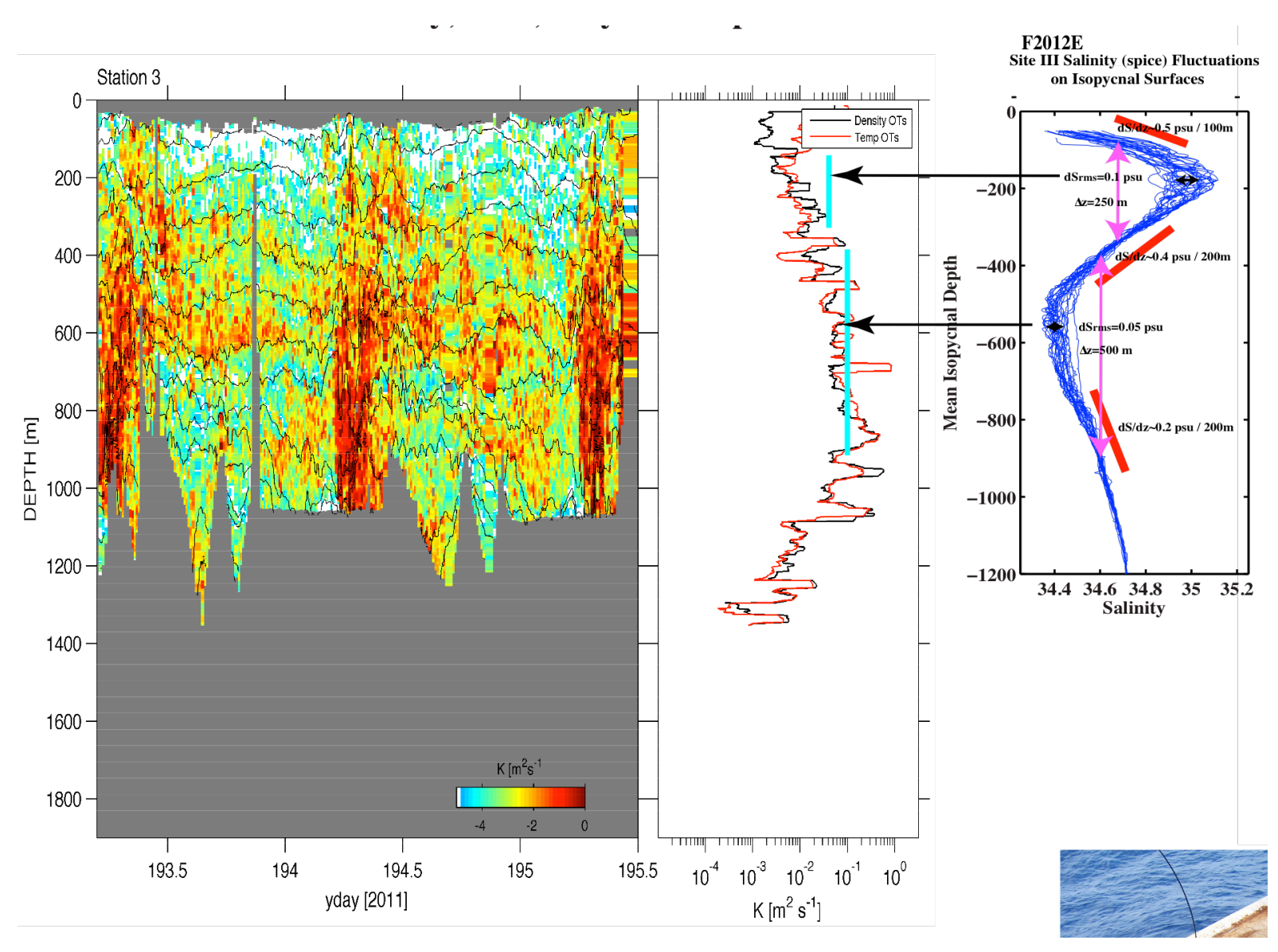

Figure 2. Dissipation rates at this outflow channel in Luzon Strait are among the highest recorded worldwide, for water depths of order $1 \mathrm{~km}$. A 48-hour depth-time series of eddy diffusivity, inferred from Thorpe scale analysis of Fast CTD profiles is given left. The average diffusivity profile (center) is the same whether based on density (black) or temperature (red) profiles. Normally, the T-S relation of the ocean is modified only on seasonal to climatological time scales. In Luzon, the large-scale T-S relation is modified with every tidal cycle. An eddy-diffusivity can be estimated just from the observed tidal variability (right)

It's not surprising that there are slight differences in the two methods of estimating diffusivity. An individual water parcel passes through Site III rather quickly. The observed salinity variability on an isopycnal (reflects the integrated effect of mixing averaged over the parcel's trajectory, as it enters the violent mixing region over Luzon Strait, and then gets "spit out" again at the end of the tidal cycle.. The Thorpe-scale estimates are local to Site III.

\section{South China Sea Process Cruise 2014}

Under Vietnam DRI funding, Researcher Drew Lucas participated in the South China Sea 2014 Process cruise aboard the Roger Revelle (22-January to 18-February; Craig Lee, Chief Scientist). The aim of the cruise was to survey the extension Kuroshio Current into the South China Sea (The Kuroshio Loop Current). The primary tools for the cruise were 1) the Triaxus 
towed vehicle (APL/UW), 2) A set of Slocum gliders, some with microstructure packages (WHOI-St. Laurent) and others with coherent $2 \mathrm{MHz}$ Nortek Aquadopp profilers (OSUShearman/Shroyer), 3) Wirewalker wave-powered profilers equipped with CTD, optics, current meter, and $\chi$-pod (Lucas, OPG/SIO), a mooring over the shelf break (WHOI- Gawarkiewicz), and typical shipboard instrumentation (underway, Met, hydrographic sonars). The general approach was a series of autonomous vehicle deployments and shipboard towed vehicle surveys to the southwest of Taiwan. A single WW profiler was deployed at the beginning of each drift. Up to 4 Slocum gliders where then deployed bracketing the WW. The gliders, using the real-time telemetered position of the WW, were navigated to maintain a array spacing around the WW to the extent possible (Fig 3,5). The Revelle concurrently sampled a repeated pattern in the context of the array utilizing the Triaxus and the Revelle hydrographic sonars.

\section{Wirewalker operations}

Wirewalker drifts:

There were four such drifts. WW performance was nominal on all drifts except the third, when a flash card failure led to the loss of all CTD and optical data but the first few hours of the drift. Current data, recorded on a different logger, were collected and showed the profiling performance was uninterrupted. The positions of the three complete WW drifts are shown in Figure 5. Time series of T, S, optics, and absolute currents are shown in Figures 6-11.

The WW drifts showed the richness of on-isopycnal compensated T/S variability in the South China Sea. In particular, the mixed layer and pycnocline were dominated by such variability in the second drift (Figure 8). This drift was well outside of the main branch of the Kuroshio loop, as evidenced by the dominance of oscillatory currents during most of the drift. Although the trajectory of the drift was nearly circular after an initial eastward translation and crossing a front that was apparent in density and optical quantities, major changes in mixed layer and pycnocline T/S relationships continued to occur. Presumably, this type of variability is common in regions where strongly advective systems (such as the Kuroshio) encounter more retentive areas such as the South China Sea.

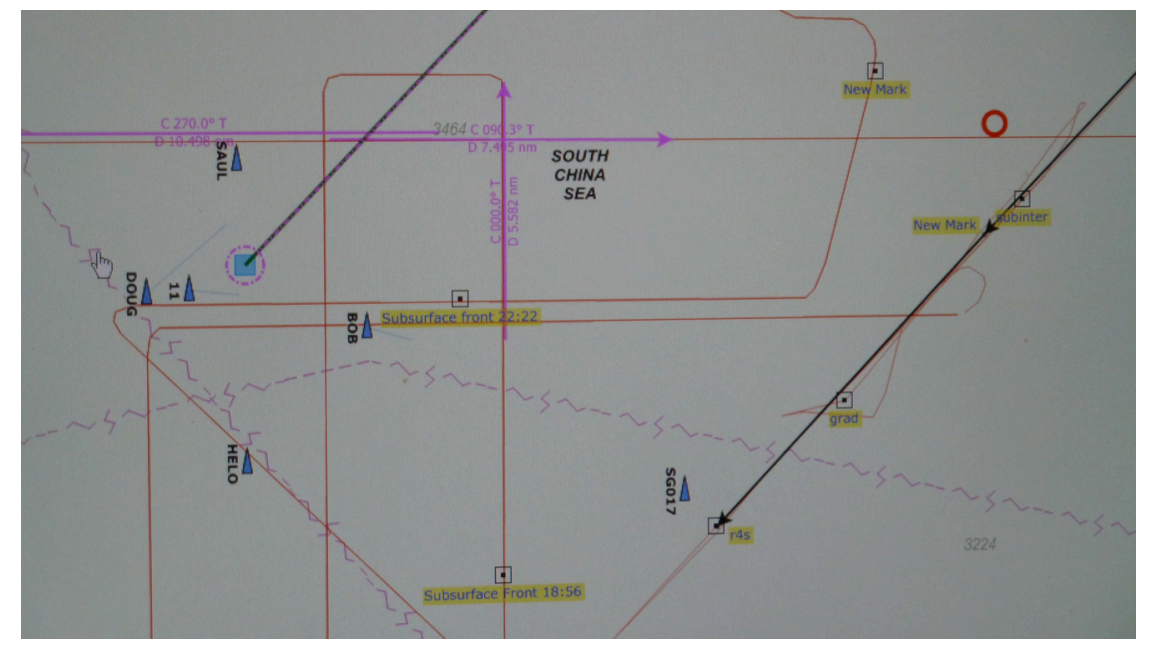

Figure 3: Screen shot of the combined activites during the CSC-14 Process study. This image shows the relative positions of the WW (\#11), four Slocum Gliders (Doug, Saul, Helo, and Bob), Seaglider (SG017) and the Revelle survey track. 
Strong spice variance impacts sound speed. Analysis is ongoing, but disentangling the physics that sets the spice variance at small spatiotemporal scales is of operational relevance to the Navy due to the modulation of the fine-scale acoustic environment.

\section{Wirewalker mooring}

In order to complement the shelf break mooring deployed by G. Gawarkiewicz (WHOI), we deployed a WW on a 150m wire just inshore of the shelf break. The mooring ground tackle was assembled from supplies the Revelle had onboard and the WW did not maintain position during the mooring. The result was poor profiling performance for approximately half of the deployment. Fishing effort was also high in the area, so the movement of the mooring could have been due to unwanted interaction with a fishing vessel. The subset of good profiling showed strong near-bed semidiurnal variability, with a surging bore-like cold pulse heading across the shelf.

\section{Wirewalker telemetry improvements}

Since the Triaxus towed vehicle operations went smoothly for extended periods of time, as a collaborative side project Jason Gobat (APL/UW) adapted a Sea Glider Iridium telemetry unit to accommodate the already implemented Wirewalker surface buoy line-of-sight radio telemetry (Fig. 4). The unit, which included a logger with rudimentary data processing and packaging and a GPS, was successful in acquiring and parsing the inductive modem stream, which transferred data from the profiler to the surface buoy. The WW Iridium telemetry system was tested on the WW moored over the continental shelf. Telemetry functioned well, although the profiling performance was at times ragged as described above.

Ongoing telemetry improvement for the Wirewalker, funded by a current DURIP, will ultimately lead to a unit designed for our specific data handling requirements. We look forward to continued collaboration between the APL/UW group headed by Craig Lee and our OPG/SIO group on autonomous telemetry development.

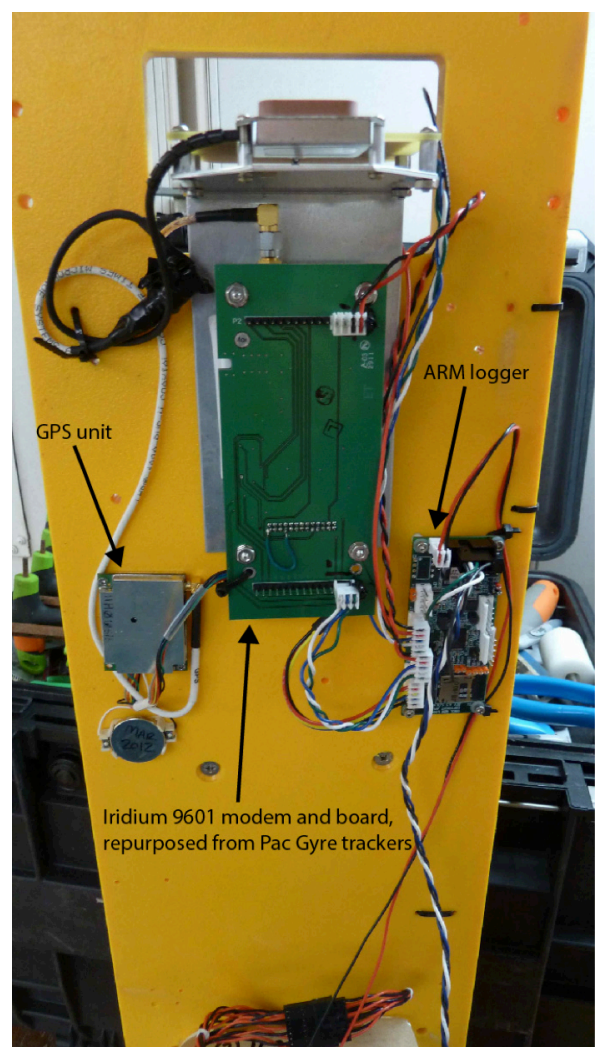

Figure 4: Repurposed spare Seaglider telemetry unit with the WW surface buoy telemetry system. The Seaglider ARM logger acquired fixes from the associated GPS, and data from the inductive modem connection with the subsurface profiler. Data was then parsed and transmitted to shore via SBD messages. The unit remains in service on the ONR ASIRI DRI. 


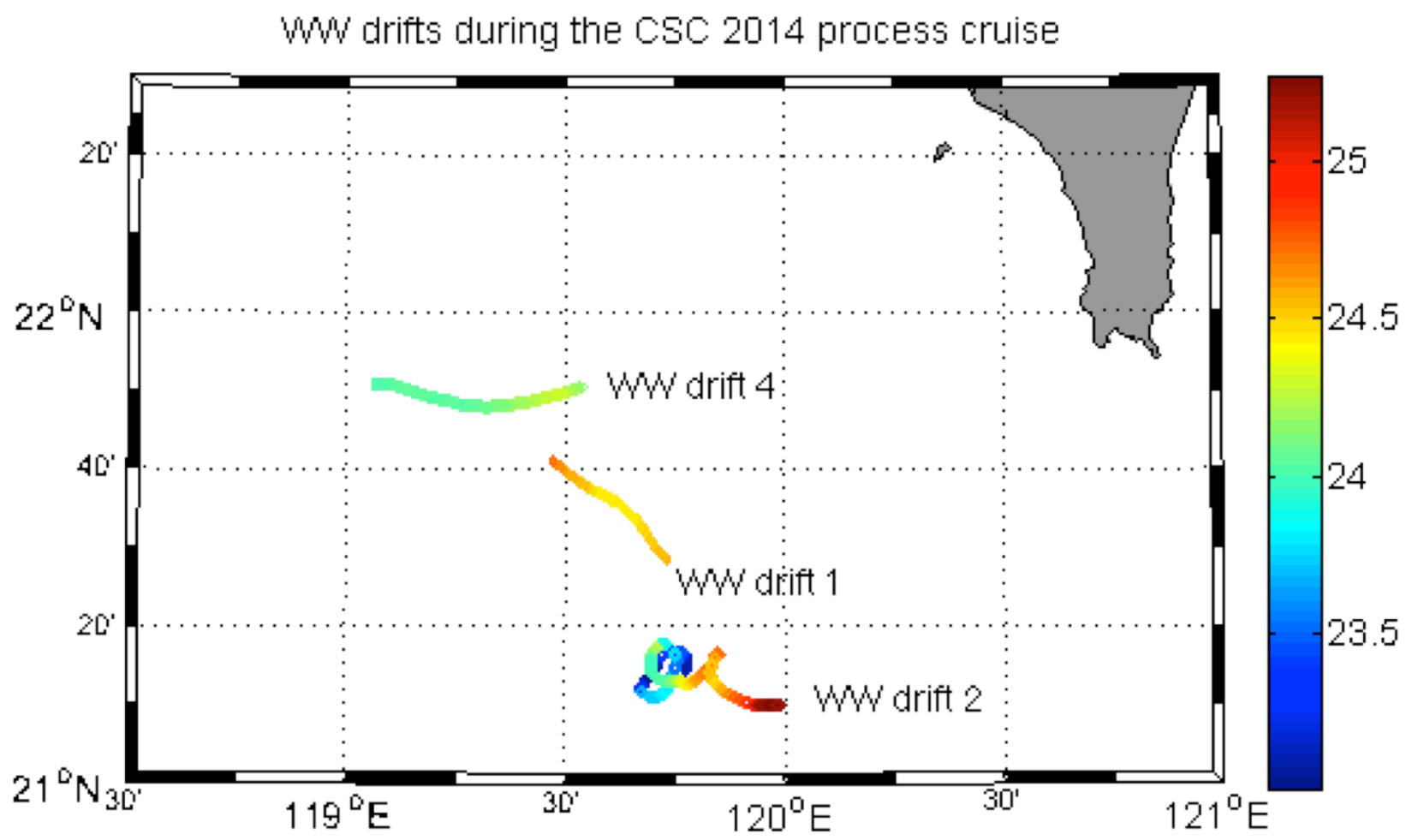

Figure 5: The drift tracks of three WW deployments during the 2014 CSC Process Cruise. Scattered on positions is near surface temperature $\left({ }^{\circ} \mathrm{C}\right)$ from the WW CTD (average of the upper ten meters). Two of the three drifts tracked flow within the SCS that was essentially uniform over the upper $200 \mathrm{~m}$ and varied little over the course of the drift, while drift two encountered a region and time where oscillatory flow (approximately 1 cycle per day) dominated the drift. 


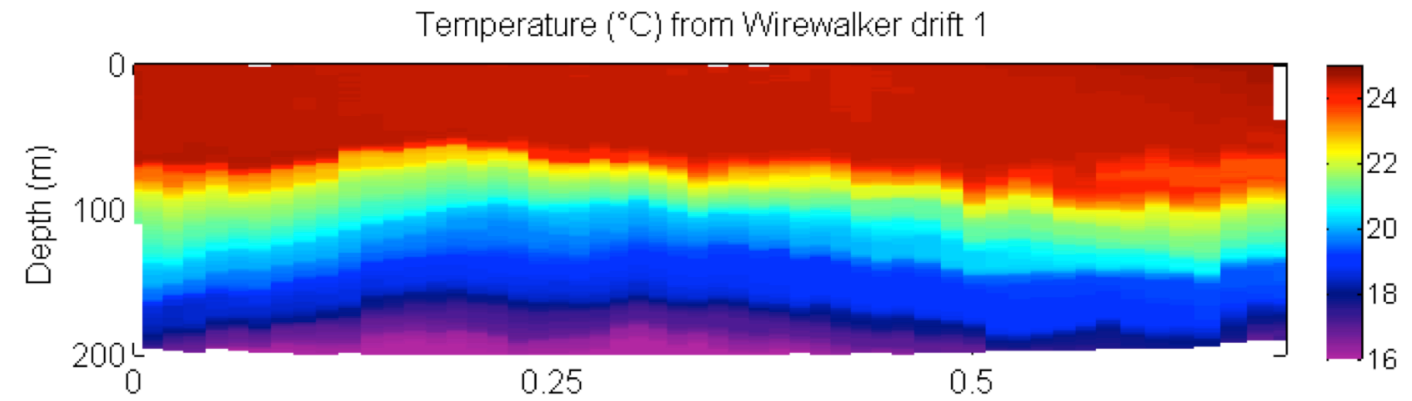

Salinity from Wirewalker drift 1

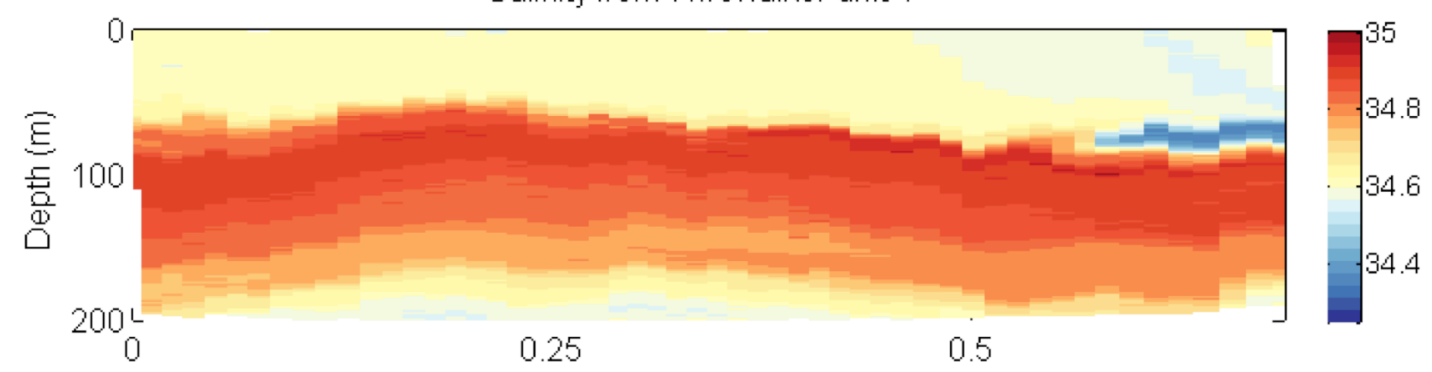

East velocity ( $\mathrm{m} / \mathrm{s}$ ) from Wirewalker drift 1

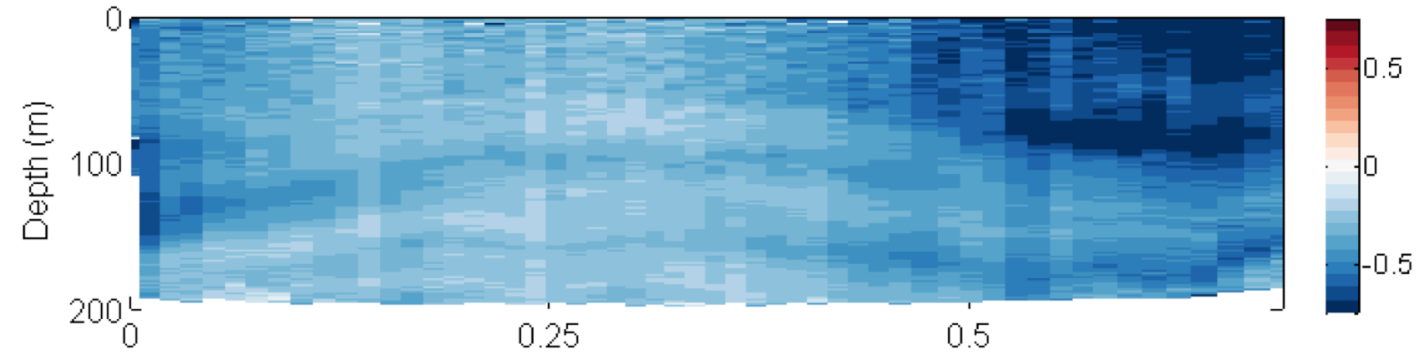

North velocity (m/s) from Wirewalker drift 1

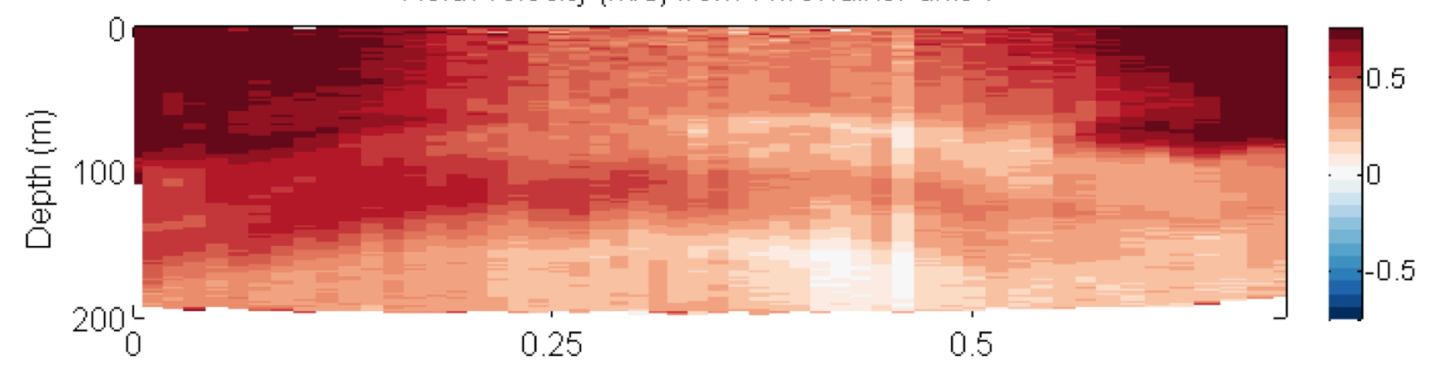

Days from 27-Jan-2014 16:05:24

Figure 6: Physical parameters with depth and time from the first WW drift. 

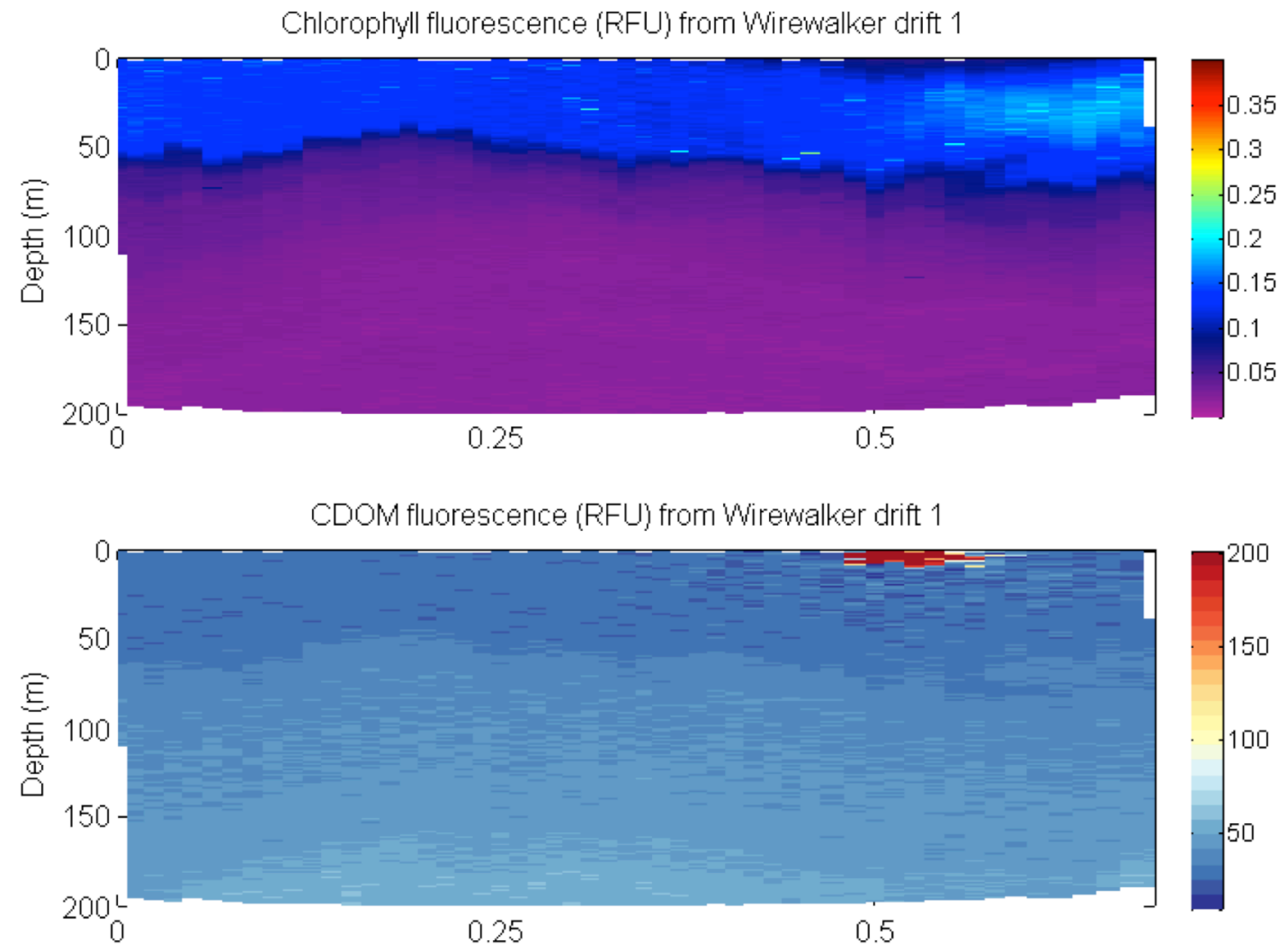

Turbidity (counts) from Wirewalker drift 1

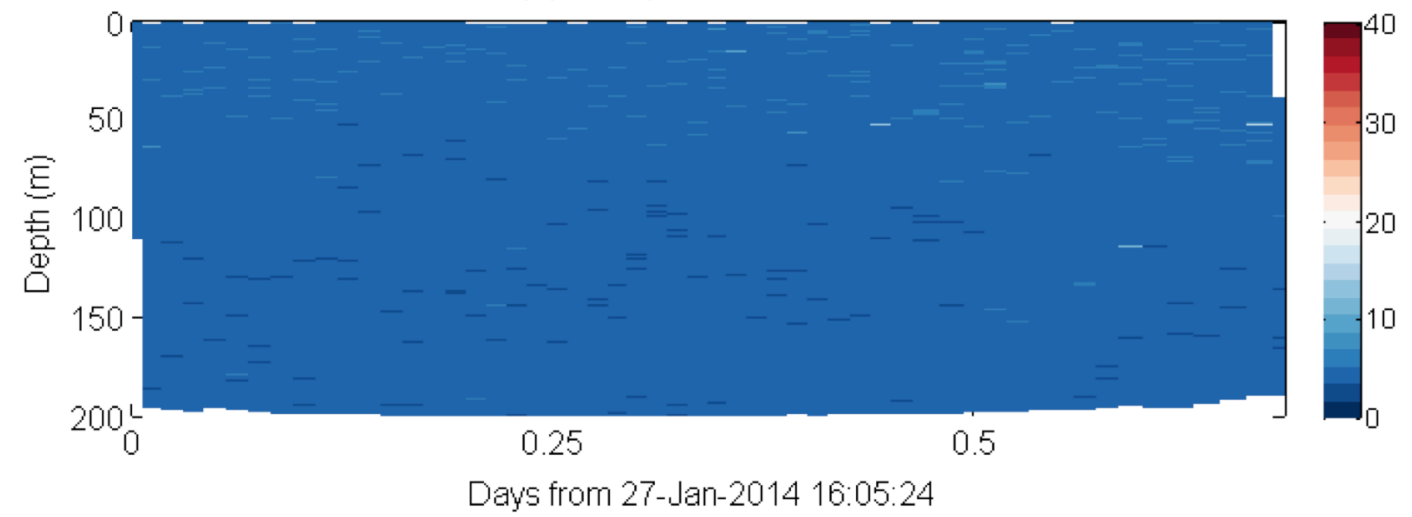

Figure 7: Optical parameters with depth and time from the first WW drift. 

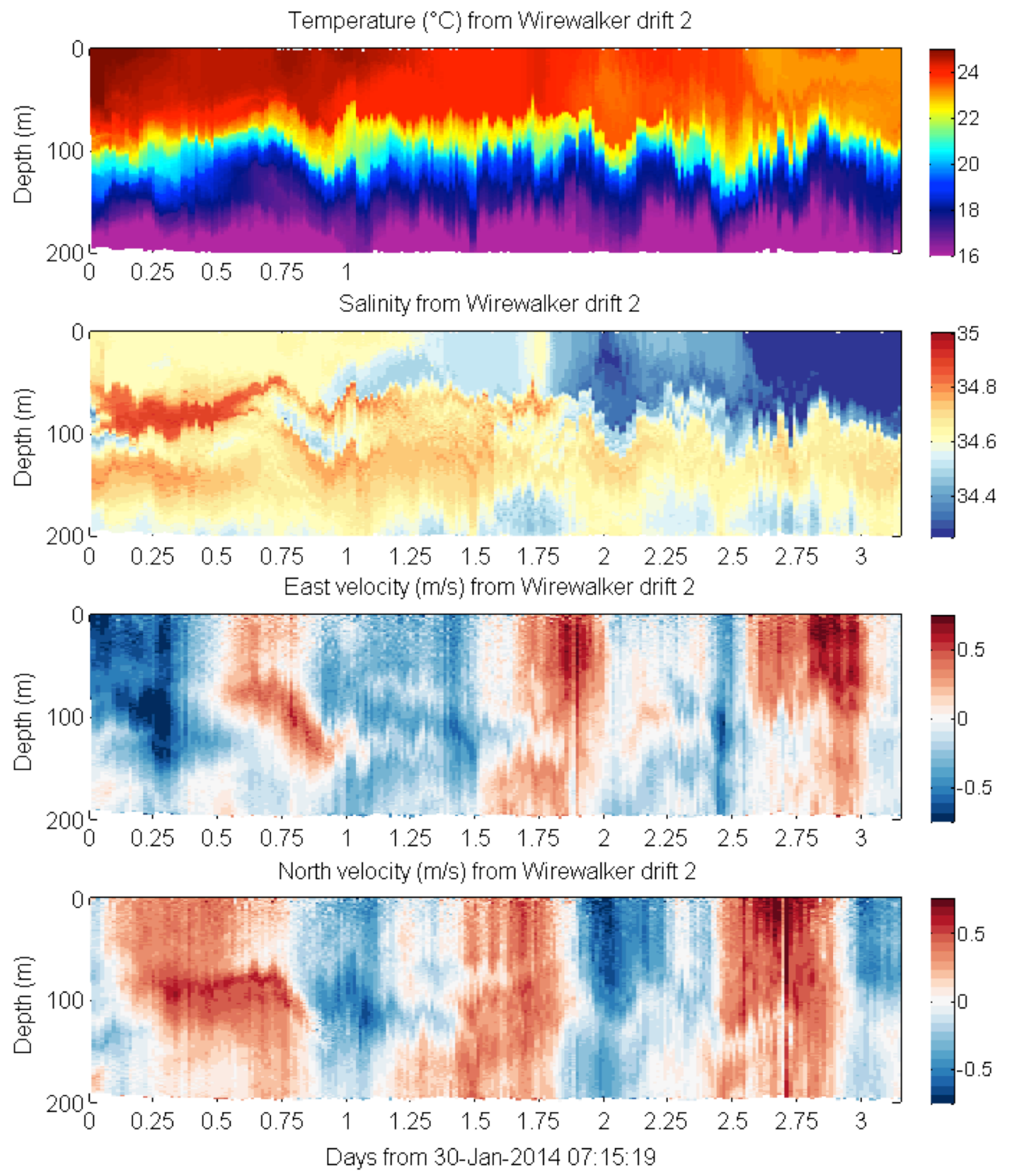

Figure 8: Physical parameters with depth and time from the second WW drift. 


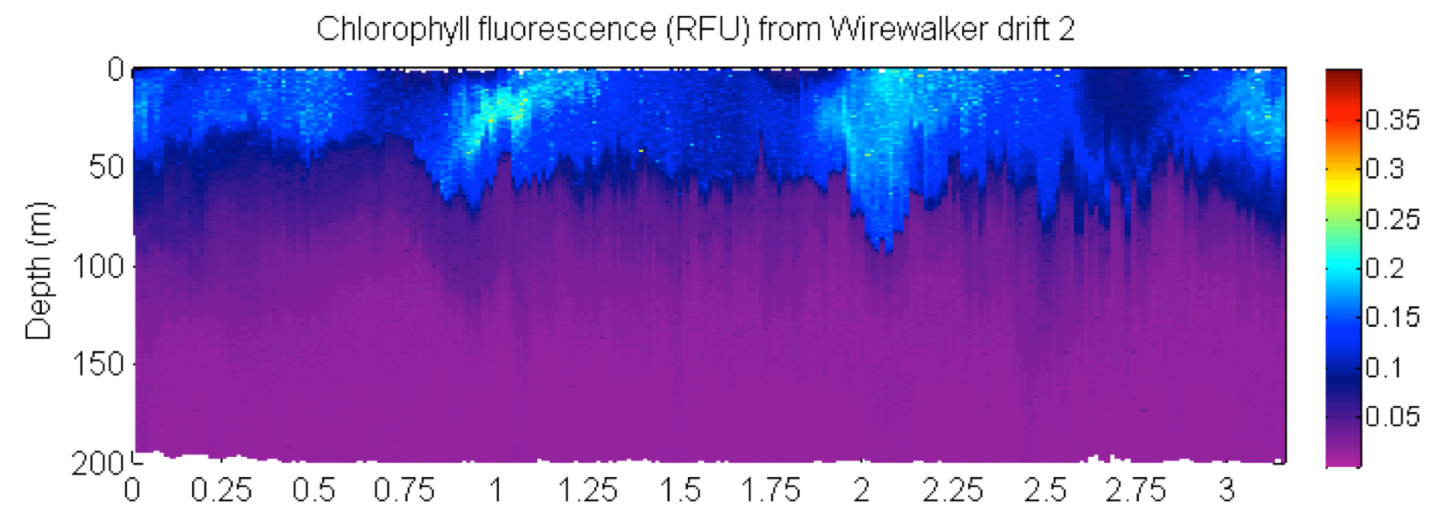

CDOM fluorescence (RFU) from Wirewalker drift 2

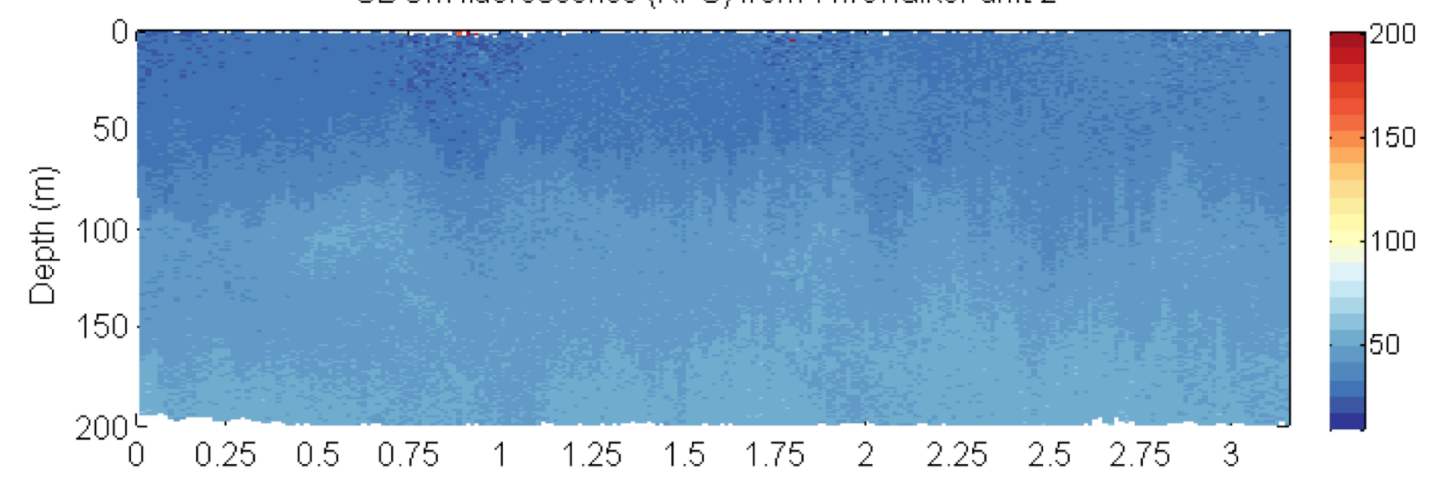

Turbidity (counts) from Wirewalker drift 2

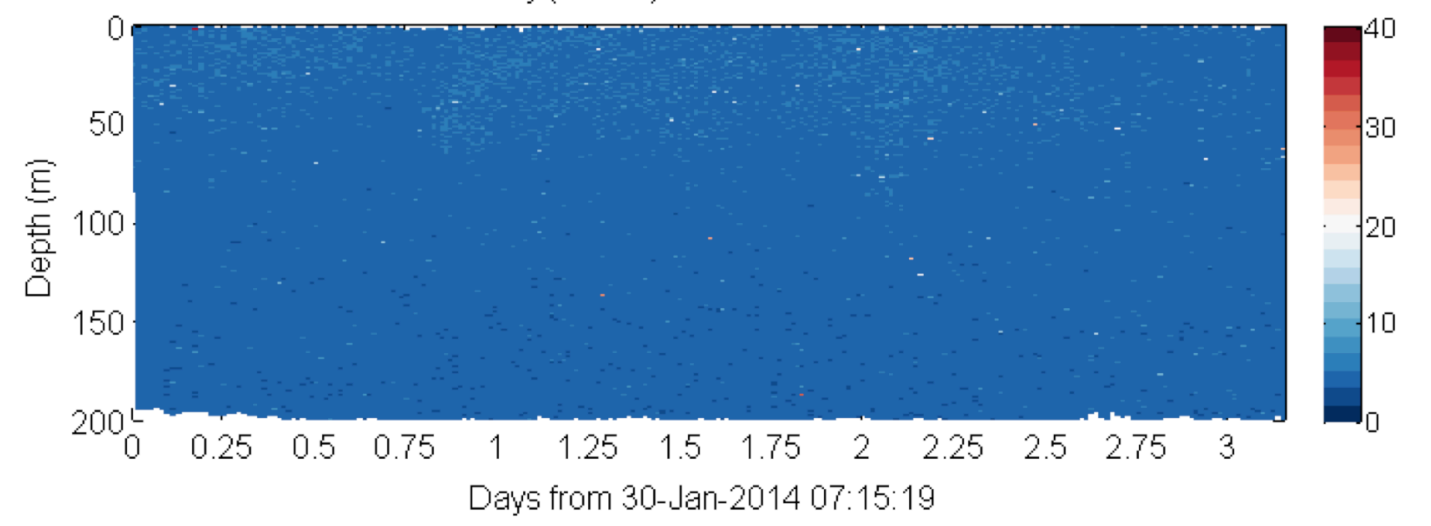

Figure 9: Optical parameters with depth and time from the second WW drift. 

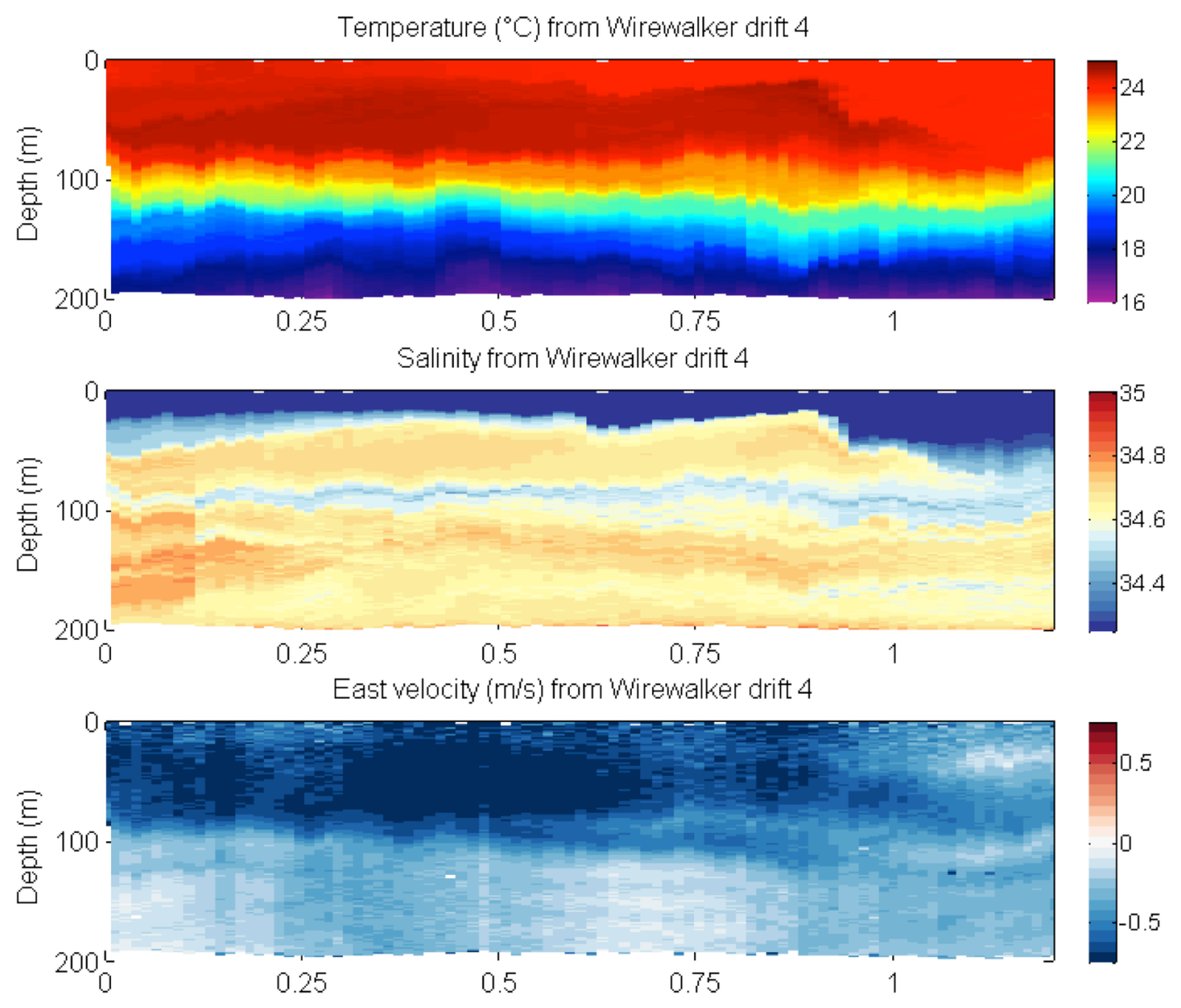

North velocity ( $\mathrm{m} / \mathrm{s}$ ) from Wirewalker drift 4

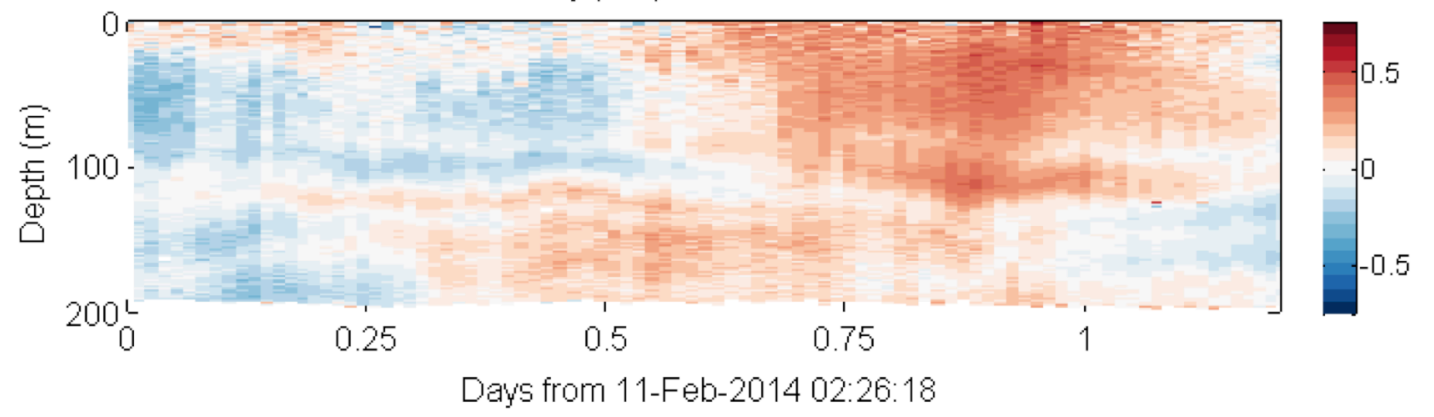

Figure 10: Physical parameters with depth and time from the fourth WW drift. 

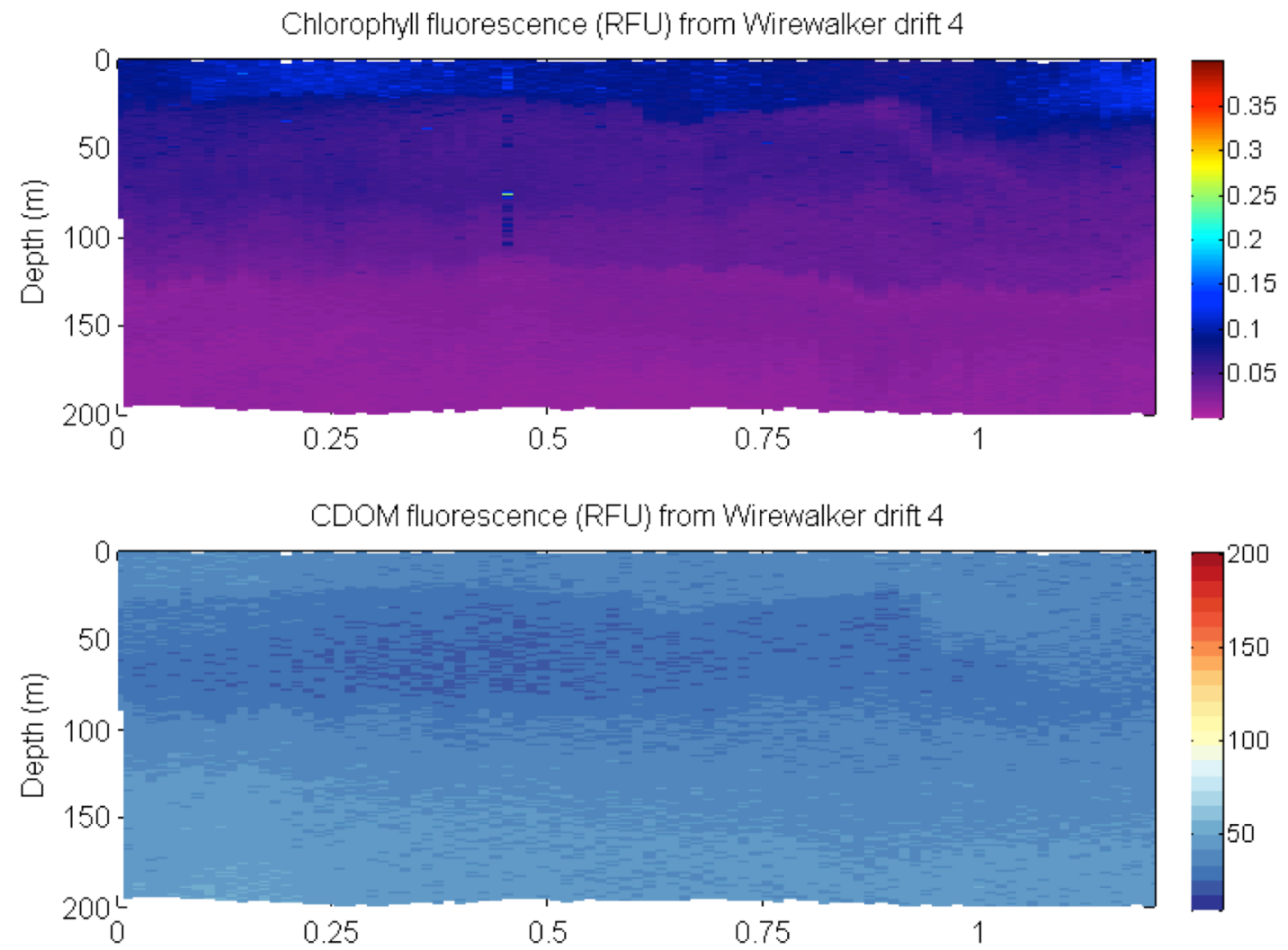

Turbidity (counts) from Wirewalker drift 4

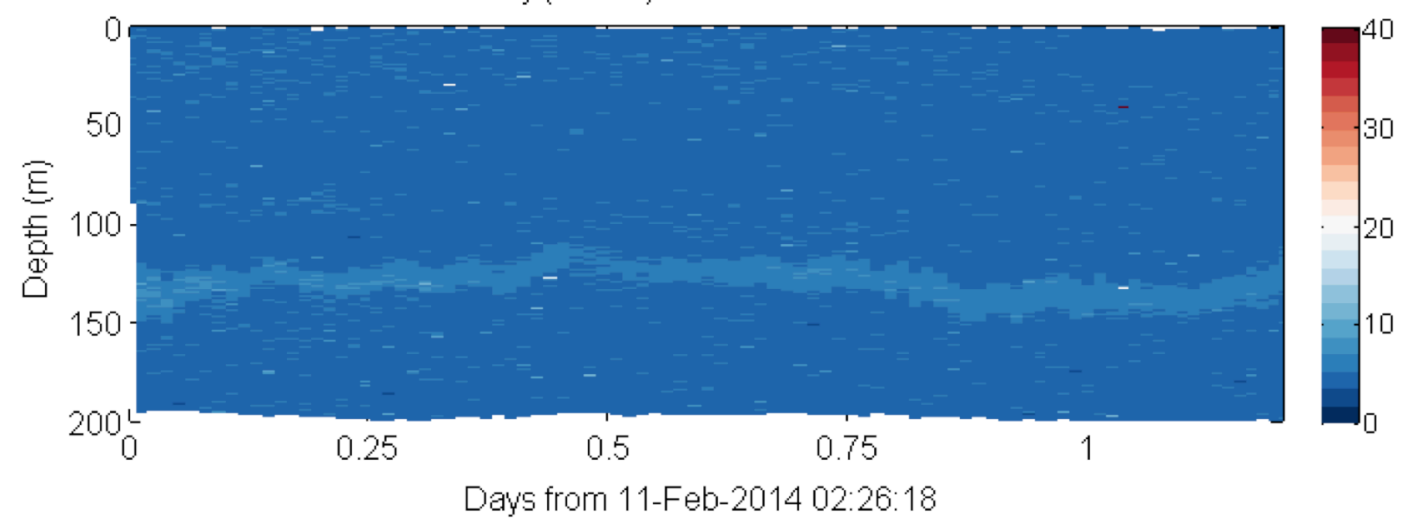

Figure 11: Optical parameters with depth and time from the fourth WW drift. 


\section{RESULTS : Luzon}

Depth integrated turbulent dissipation levels in this outflow channel approach $10 \mathrm{~W} / \mathrm{m}^{2}$, perhaps the greatest yet reported, globally. Ruth Musgrave is modeling these flows using 2-D and 3-D codes, to aid in the interpretation of these observations.

\section{RESULTS : Winter SCS}

Researcher Drew Lucas is working with colleagues on the cruise to produce an integrated picture of sub-mesoscale variability in the region.

\section{IMPACT/APPLICATIONS}

The objective is to understand the physics at Luzon and the SCS well enough that accurate numerical predictions for similar sites can be obtained, globally.

\section{TRANSITIONS}

Given experience with sub-mesoscale flows obtained by other DRI PIs in spring 2013, we completed a sub-mesoscale-oriented experiment using Wirewalker floats in January 2014.

\section{RELATED PROJECTS}

ASIRI DRI, Sub-Mesoscale DRI

\section{PUBLICATIONS}

Pinkel, R., M. A. Goldin, J. A. Smith, O. Sun, A. Aja, M. N. Bui, T. Hughen. The Wirewalker, a vertically profiling instrument package powered by ocean waves. J Atmospheric and Oceanic Tech., 2010.

Smith, J.A., R.Pinkel, M.Goldin, O.Sun. S, Nguyen, T.Hughen, M. Bui, and T.Aja. Wirewalker Dynamics. J Atmospheric and Oceanic Tech., 2011. 